\title{
Exploring the Relationship between Self-Regulated Learning and Reflection in Teacher Education
}

\author{
Dawn Buzza \\ Wilfrid Laurier University \\ Donna Kotsopoulos \\ Wilfrid Laurier University \\ Julie Mueller \\ Wilfrid Laurier University
}

Megan Johnston

\begin{abstract}
Literature on teacher learning has shown links between being a selfregulated learner, reflecting effectively on one's own practice, and being described as an "adaptive expert". For instance, the metacognitive skills needed for effective reflection on teaching practice are seen as critically important to developing adaptive expertise in the context of the highly complex classroom environment. Similarly, self-regulated learning is often defined, at least in part, in terms of using metacognitive skill to adapt one's approach to complex learning situations or problems. Although there is rich literature on reflective practice in teacher education, less is known about measuring teachers' self-regulated learning or the relationship between self-regulated learning and teacher reflections. This research examines reflective practice and self-regulated learning through pre-service teachers' written reflections. The study makes a novel adaptation of a rubric designed to evaluate pre-service teachers' reflections to measure self-regulated learning. Findings suggest that the rubric could also be useful in understanding the selfregulated practices of pre-service teachers.
\end{abstract}

\section{Introduction}

Research on teacher reflection has shown that developing a reflective stance can help teachers to systematically improve their practice. Hammerness et al. (2005), and others (e.g., National Research Council, 2000) have argued that reflection can help beginning teachers to overcome the limitations of tacit knowledge about teaching and learning that they have constructed through their previous experience as students (i.e., the problem of "the apprenticeship of observation" (Hammerness, et al., 2005). According to these authors, reflection, or metacognition (Flavell, 1979), is critically important to the development of "adaptive expertise" (National Research Council, 2000) in the context of the extremely complex professional activity of teaching (Hammerness et al., 2005; Shulman, 1987). Bransford, Derry, Berliner, Hammerness and Beckett (2005) 
define adaptive experts as teachers who show both efficiency and innovation in their pedagogy.

Similar to the way in which effective teachers can be described as adaptive experts, effective learners are often depicted as adaptive experts in the literature on self-regulated learning (SRL) (Winne \& Hadwin, 2008; Zimmerman \& Schunk, 2001). Self-regulated learners are commonly described as metacognitively, motivationally, and behaviourally engaged in the learning process. Given that self-regulated learners are experts at managing complex learning tasks because they are self-aware, goal-directed, strategic, and able to monitor and motivate their own learning, teachers who manage their pedagogical practices in similar fashion may also be seen as adaptive experts at their craft.

There are seemingly clear parallels between the ways in which researchers describe teacher reflection and learners' SRL, particularly when these processes are conceptualized as problem solving cycles. The current study examines how both constructs might be assessed through an analysis of pre-service teachers reflections during a one-year teacher education program. We adapted a rubric designed originally for evaluating the quality of pre-service teachers reflections on their own practice lessons (Appendix A, Ward \& McCotter, 2004) to determine its usefulness for also measuring their developing SRL. Pre-service teachers' reflections were evaluated for "quality of reflection" using this rubric and also for presence of SRL components using an SRL Rating Scale (Appendix B) designed for this study. The research question guiding our study is as follows: Given the close conceptual relationship between reflection and self-regulation, can a reflectionorientated rubric also be useful in assessing teachers' SRL?

\section{Theoretical Context and Relevant Literature}

Building on theoretical work by Dewey (1933) and Schön (1983), many frameworks for understanding the nature and functions of reflection have been formulated, critiqued and researched in recent years (see Hatton \& Smith, 1995; Ward \& McCotter, 2004; and Yost, Sentner \& Forlenza-Bailey, 2000). Distinctions have been made between kinds of teacher reflection, including differences in time frames, such as reflection-on-action versus reflection-in-action (e.g., Schön, 1983); differences between reflective thought and reflective action (Gore \& Zeichner, 1991); purposes and qualitative levels of reflection such as a the "technocratic" approach of Cruickshank et al. (1981); and critical reflection models where highly reflective teachers begin to challenge existing social, cultural, political or moral norms within education (Collier, 1999; Dinkelman, 2000; Hatton \& Smith, 1995; Sparks-Langer, Simmons, Pasch, Colton \& Starko, 1991). Some recent models also view reflection in terms of problem solving, where reflective teaching is seen as a recursive process of teaching actions/ events, problem identification, improvement goal definition, and further action (Yost, Sentner \& Forlenza-Bailey, 2000).

Most contemporary models of SRL involve learners' application of metacognitive knowledge and control, intrinsic motivation, and strategic knowledge and skills in learning situations (Winne \& Hadwin, 1998; 2008; Winne \& Perry, 2000). These authors refer to learners' metacognitive knowledge and control as awareness of their strengths and weaknesses as learners and the ability to apply strategies effectively to manage challenging tasks. These metacognitive and strategic aspects of SRL are also captured in most recent perspectives on teacher reflection (Kremer-Hayon \& Tillema, 1999). In drawing comparisons 
between teacher reflection and SRL, it may be the conceptualization of reflection in terms of recursive problem-solving cycles that is most useful. For instance, Winne and Hadwin (1998) described SRL in academic tasks as unfolding across the following four flexibly-sequenced phases: 1) task definition; 2) setting goals and plans; 3) enacting the task using learning and study tactics; and 4) adaptations, in which "cognitive conditions" such as task and domain knowledge and motivational factors are reassessed in light of metacognitive judgments about how well current strategies are working.

As these recursive cycles are repeated over time and across tasks, effective learners, and also highly reflective teaching practitioners, are gradually developing the adaptive expertise that is the hallmark of SRL and of master teachers. Although many teacher education programs provide their students opportunities to practice metacognitive skills through program elements such as constructivist methods that link theory with practice, inquiry or action research, dialogue, and/or reflective writing experiences (Yost et al., 2000), questions have been raised as to the outcomes of these program features, including lack of empirical support for their effectiveness in actually fostering meaningful reflection or learning (Hatton \& Smith, 1995; Ward \& McCotter, 2004 ).

Hatton and Smith (1995) suggest that beginning teachers may develop the ability to reflect on action before they can effectively engage in reflection-inaction: "What may be hierarchical is a developmental sequence, starting the beginner with the relatively simplistic or partial technical type, then working through different forms of reflection-on-action to the desired end-point of a professional able to undertake reflection-in-action" (p.45) - again, the notion of a developing or emergent "adaptive expertise" is also apparent in Hatton and Smith's perspective. Consequently, pre-service teachers may not be able to advance to the stage where reflection-in-action occurs, given the short duration of oneyear professional preparation programs.

While much research literature has demonstrated the importance of SRL in academic learning including the ways it can be promoted by both in-service and pre-service teachers (Perry \& VandeKamp, 2000), less is known about links between SRL and teacher reflection. Additionally, research that documents realtime, contextually situated assessment measures of students' SRL is limited (Perry, 2002; Taylor \& Corrigan, 2007; Tillema \& Kremer-Hayon, 2002; Winne \& Perry, 2000).

\section{Methods}

\section{Participants}

The participants in this study were the pre-service teachers in a program based on a professional development school model. The program prepares students for certification at the primary/junior level. In this program pre-service teachers are assigned to the same school, referred to as a Professional Development School (PDS) site, for the entire school year. They spend two "field days" each week at their PDS sites during periods when they are taking university classes. During the year when the study was conducted, university classes ran for five weeks between each of four practicum placements. One of the compulsory university courses is a Professional Learning Seminar, which takes place on one of the two field days each week, throughout the school year. One of the advantages of the PDS teacher education model is the immersion in one school for so much time over 
the school year. Pre-service teachers become familiar with many aspects of life in their school, become part of its culture, and are able to observe a wide range of classrooms and pedagogical activities that they would not experience in a traditional teacher education program. As one of the requirements of the Professional Learning Seminar, pre-service teachers responded in writing to weekly reflective questions as they observed, practiced and interacted in their school environments throughout the year.

At the beginning of the program, 71 pre-service teachers were invited to participate in the study by allowing the research team to use their reflective question responses as data. All 71 consented to participate; however, two of them withdrew from the program during the academic year. In the remaining group there were 8 males and 61 females. Seven of the female participants did not give us permission to use direct quotes from their responses. The age of participants ranged from 21 to 46, with a mean age of 28.1, SD =6.27. A random sample of eight cases was analyzed using a multiple case study approach (Merriam, 1988, 1998; Stake, 1995, 2000; Yin, 1994).

\section{Data sources}

The data collected for this study includes written responses to 5 of the 20 reflective questions that were addressed by TECs over the course of the year. The questions were:

1. Assessment-centered teachers use information from ongoing assessment to improve their teaching and to assist students in becoming increasingly more metacognitive, self-directed and independent. Discuss some observations you have about how assessment in your PDS is supporting these goals.

2. As an elementary teacher you are expected to have a wide and diverse range of content knowledge across the curriculum. What anticipations and reservations do you have about this expectation? What have you observed in your PDS about this expectation?

3. Discuss some of the different types of pedagogical choices you have observed in your PDS. Discuss the factors that influence the decisions you will make regarding pedagogical choices.

4. Learner-centered teachers differentiate teaching and learning to support the unique learning needs and interests of all students. Discuss and give examples of the opportunities you have had in your PDS to provide differentiated support for students

5. How has the inquiry model supported you in learning to teach?

These five questions were chosen because they focus on specific knowledge and skill areas that pre-service teachers are developing in the program. Other questions that were not included in this investigation focused on program components such as technology integration, pre-service teachers' perceptions of the PDS model, ways in which professional and ethical standards were demonstrated in their PDS sites, and their perceptions and thoughts concerning standardized testing. Results from these other questions are reported elsewhere (Author et al., 2008a; Author et al., 2008b). Responses were not regulated in terms of length, were viewable only by the individual pre-service teachers and the researchers, and were graded on a "complete/incomplete" basis only. 


\section{Data coding and analysis}

Reflection Rubric. The rubric developed by Ward and McCotter (2004) was adapted for use in this investigation as a means of evaluating the reflective question responses, and as a potential indicator of SRL. This rubric was designed to evaluate reflections on the dimensions of Focus (i.e., What is the focus of concerns about practice?), Inquiry (i.e., What is the process of Inquiry?) and Change (i.e., How does inquiry change practice and perspective?).

The original rubric defined four levels to distinguish the quality of reflections on each of these three dimensions, as follows: (1) Routine (selfdisengaged from change), (2) Technical (instrumental response to specific situations without changing perspective), (3) Dialogic (inquiry part of a process involving cycles of situated questions and action, consideration for others' perspectives, new insights), and (4) Transformative (fundamental questions and change) (Ward \& McCotter, 2004). Level 4, or Transformative level reflections, are said to include personal involvement with fundamental pedagogical, ethical, moral, cultural, or historical concerns and change.

The fourth (Transformative) level was omitted from the rubric in the present study for two reasons. One reason is that in our preliminary data analyses it was found that none of the reflective question responses in our sample reached the Transformative level. This finding supports those of Ward and McCotter (2004, p.253), where pre-service teachers often reached the Transformative level in reflections on theoretical readings, but rarely in reflections on teaching. The second reason for not including the Transformative level in our adaptation of the rubric was that we were investigating how well assessments of pre-service teachers' reflections using this tool can be aligned with assessments on SRL. Conceptually, both reflection and SRL can be seen as adaptive expertise in differing, yet overlapping arenas of activity within a pedagogical problem-solving cycle (teacher reflection being focused on teaching events and SRL being focused on learning events). Although they may represent an important aspect of teacher development, Transformative level reflections may represent an extension of teaching expertise into considerations of one's personal philosophical stance and, as such, would not necessarily be expected to align with SRL.

Further, we propose that the pedagogical problem-solving cycle is iterative rather than recursive in that reflection-on-action relating to learning or teaching events should result in additional reflection-in-action, which then spawns more reflection-on-action, and so forth. The pedagogical problem-solving cycle is iterative in that reflection informs all parts of the cycle. If we conceptualize reflection within a pedagogical problem-solving cycle, highly effective reflection, or reflection-in-action, should be captured at the dialogic level on Ward and McCotter's (2004) rubric.

SRL Rating Scale. The rating scale developed for this investigation was based directly on SRL components' definitions as these are frequently described in contemporary literature (e.g., Winne \& Hadwin, 2008; Winne \& Perry, 2000; Zimmerman, 1990). Metacognitive knowledge was defined as self-awareness and monitoring of: a) one's current knowledge and skill; b) development of expertise; and c) how to regulate engagement in tasks to optimize learning processes and outcomes. Intrinsic Motivation was defined as including the following: a) a belief in 
incremental learning; b) placing a high value on personal progress and deep understanding; c) a lack of concern for impressing others or being better than peers; d) high efficacy for learning; and e) attributions that link outcomes to effort and use of effective strategies (i.e., factors under one's own control). Strategic Knowledge and Behaviour was defined in terms of the teacher candidate's response to challenging tasks, as: a) choosing from a repertoire of tactics those best suited to the task or problem at hand; b) applying those tactics appropriately; c) changing approach as needed; and d) using resources such as peers, mentors and materials effectively.

On each of the three dimensions of Metacognitive Knowledge, Intrinsic Motivation, and Strategic Knowledge and Behaviour, responses to the five reflective questions were rated on a three-point scale. The three points were defined as: (1) Minimal or no evidence of the SRL dimension; (2) Moderate-to-high level of SRL dimension (may be strong but only in one instance or place within the response); and (3) High level of SRL dimension (shown in two or more places within the response).

In comparing outcomes on the Reflection Rubric to those on the SRL Rating Scale, Dialogic level reflections were considered to be high-SRL and Routine level reflections were considered low-SRL. Thus, Dialogic responses were coded as level 3, Technical responses were coded as level 2, and Routine responses were coded as level 1 .

The average Reflection Rubric score, across all five reflective questions, was computed for each participant. Similarly, the average SRL Rating Scale score, across all five reflective questions, was computed for each participant. Difference scores were calculated for each participant between the average Reflection Rubric scores and the SRL Rating Scale scores to examine the range between averages. The means of participants' total average scores for both the Reflection Rubric and the SRL Rating Scale were also calculated and compared.

Average Metacognitive Knowledge scores from the SRL Rating Scale, and Focus, Inquiry, and Change scores from the Reflection Rubric, across all five questions were computed and compared. Additionally, the means of participants' total average scores for Metacognitive Knowledge on the SRL Rating Scale, and for Focus, Inquiry, and Change scores on the Reflection Rubric were computed and compared. The purpose of this comparison was to see if scores from components of the Reflection Rubric were consistent with Metacognitive Knowledge scores on the SRL Rating Scale. Intrinsic Motivation and Strategic Knowledge and Behaviour scores from the SRL Rating Scale were not seen as mutually independent from the Metacognitive Knowledge score as indicators of SRL, and thus were not individually compared to the specific sections of the Reflection Rubric.

Two authors evaluated the random sample first individually. Coding differences were discussed between coders, and amongst all authors. Consensus was reached and results of the coding are reported herein. We present the scores outlined above in our Results section, as well as specific examples of high and low SRL. The particular examples were selected for their evidentiary potential.

\section{Results}

Results from the average Reflection Rubric scores and the average SRL Rating Scale scores (see Table 1) suggest that Ward and McCotter's (2004) Reflection 
Rubric may also be effective for examining SRL in pre-service teachers. Total averaged scores across participants for the SRL Rating scores were 6.4 and for the Reflection Rubric were 6.125 with a difference score of 0.275 . Scores for the SRL Rating were higher for cases one, three, and six.

\begin{tabular}{|c|c|c|c|}
\hline Case & $\begin{array}{c}\text { Average SRL } \\
\text { Score }\end{array}$ & $\begin{array}{c}\text { Average Reflection } \\
\text { Score }\end{array}$ & Difference Score \\
\hline 1 & 4.6 & 5.4 & -0.8 \\
\hline 2 & 6.0 & 5.8 & 0.2 \\
\hline 3 & 7.2 & 7.6 & -0.4 \\
\hline 4 & 5.4 & 5.4 & 0.0 \\
\hline 5 & 7.4 & 6.4 & 1.0 \\
\hline 6 & 6.0 & 7.6 & -1.6 \\
\hline 7 & 7.2 & 6.2 & 1.0 \\
\hline 8 & 7.4 & 4.6 & 2.8 \\
\hline Total & 6.4 & 6.125 & 0.275 \\
\hline
\end{tabular}

Table 1. Average Self-Regulated Learning and Reflection scores across five reflective questions for individual cases and for all cases.

Averaged total scores across participants for Metacognitive Knowledge, Focus, Inquiry, and Change were 2.225, 2.175, 1.95, and 2.025 respectively (see Table 2). The close alignment of these results further supports the potential usefulness of the Reflection Rubric for evaluating SRL. Although our sample size prevents us from making any claims to statistical significance of our findings, the closely linked results are sufficiently compelling to warrant more research into this connection between reflection and SRL and the simultaneous usefulness of reflection-oriented rubrics to also evaluate SRL.

\begin{tabular}{|c|c|c|c|c|}
\hline Case & $\begin{array}{c}\text { Average MK } \\
\text { score }\end{array}$ & $\begin{array}{c}\text { Average } \\
\text { Focus } \\
\text { Score }\end{array}$ & $\begin{array}{c}\text { Average } \\
\text { Inquiry } \\
\text { Score }\end{array}$ & $\begin{array}{c}\text { Average } \\
\text { Change } \\
\text { Score }\end{array}$ \\
\hline 1 & 1.8 & 2 & 1.6 & 1.8 \\
\hline 2 & 2 & 2 & 2 & 2 \\
\hline 3 & 2.2 & 2.6 & 2.6 & 2.4 \\
\hline 4 & 1.8 & 2 & 1.6 & 1.8 \\
\hline 5 & 2.8 & 2.2 & 2 & 2.2 \\
\hline 6 & 2.4 & 2.6 & 2.4 & 2.6 \\
\hline 7 & 2.2 & 2.4 & 1.8 & 2 \\
\hline 8 & 2.6 & 1.6 & 1.6 & 1.4 \\
\hline Total & 2.225 & 2.175 & 1.95 & 2.025 \\
\hline
\end{tabular}

Table 2. Average scores on individual components of the Reflection Rubric and the Metacognitive Knowledge component of the Self-Regulated Learning instrument

\section{Example of reflection rubric coding indicating low SRL}

The following example describes the ways in which one teacher candidate's five reflection responses were coded using the Reflection Rubric. Of the fifteen 
Reflection Rubric codes assigned to this set of responses (i.e., levels for Focus, Inquiry and Change dimensions on the five reflective question responses), eight were coded as Routine and seven as Technical. None of the responses were judged as Dialogic level on any of the three dimensions. This teacher candidate's responses were typified by a focus on concerns for her own workload and performance, including avoiding blame for failures or weaknesses, and consideration of questions related to specific situations without using them to change her perspectives. For instance, in responding to Question 2, she focused most of her comments on the demands of teaching, which she anticipated would be daunting for her in her first job. Her analyses often tended to be definitive and generalized, without acknowledging the complexity of issues or implying openness to new insights. Responses seemed to be technical or even disengaged, as if the analysis were being done for its own sake, rather than as a means to further learning or understanding.

The approach taken by this teacher candidate is characteristic of students who are described as low-SRL in academic contexts (Paris \& Newman, 1990; Perry \& VandeKamp, 2000). There was an expressed lack of efficacy for learning, where outcomes were seen as beyond her control, and where her own efforts were expected to result in limited success. She did not address the reflective questions as opportunities to understand more deeply or gain new insights that could improve her teaching practice, nor did she mention strategies for increasing her learning or competence; instead her comments took the form of analyses and critiques of classroom practices that demonstrated a distancing of her own learning from the situations she described.

\section{Example of reflection rubric coding indicating high SRL}

According to the codes assigned on the Reflection Rubric, the responses provided by this teacher candidate demonstrated that she clearly saw each reflection as an opportunity to develop deeper understanding and increase her competence. She showed confidence in her strategies for addressing learning challenges in each area of teaching practice referred to in the five questions. Using the Rubric, seven Dialogic and eight Technical ratings were given. Routine reflections were not found in any of her responses.

In her reflection on Question 1 she described how she used formative assessment with her students as part of an inquiry process involving cycles of situated questions and action, where she gained new insights about her teaching and her students' learning, and which she saw as leading to improvements in practice. Her goal-directed, strategic approach and self-efficacy as a learner in this situation was apparent. While not all of this teacher candidate's reflections reached the Dialogic level, they demonstrated highly engaged, intrinsically motivated use of metacognition to analyze task demands in relation to her own strengths and limitations - all of which are hallmarks of self-regulated learning. In describing how engaging in formal inquiry (action research) has supported her in learning to teach, she commented:

I have had to investigate what questions are more important, what issues need to be explored and what needs the students may have. Through the inquiry model, I believe that I am able to gear my teaching towards students with more of a certainty, based in my research as well as the research of those before me. It is an 
incredible tool as well as allowing me as a teacher to have insight into my students.

\section{Discussion}

The close scores between the Reflection Rubric and the SRL Rating Scale support the suggestion of conceptual parallels in reflective practice literature (e.g., Hammerness, et al., 2005) that characterizes teachers as adaptive experts and the SRL literature that describes high levels of SRL as "adaptive expertise." We found in five of our cases that pre-service teachers had higher SRL Rating scores than Reflection Rubric scores. Given that the Bachelor of Education degree was in most cases the second or third degree for participants in this sample, this is not a surprising finding; pre-service teachers can be expected to be more expert as learners than they are as teachers. As "adaptive expertise" in learning contexts, SRL should be quite well developed by the time these pre-service teachers have completed their first degree.

We intentionally omitted the Transformative level from our analysis, in our adaptation of Ward and McCotter's (2004) rubric. This was in response to the authors' suggestion that this type of reflection may not be possible during preservice teacher education. Pre-service teachers are new teachers and thus are only at the beginning of the proposed pedagogical problem-solving process discussed earlier, which moves iteratively between reflection-in-action and reflection-onaction. Indeed, no teacher candidate's reflection was determined to have reached the Transformative level of reflection during the initial coding in this study.

The Transformative reflection from the Reflection Rubric is a highly critical (in the sense of taking a critical perspective as opposed to being the most important) and sophisticated type of reflection. This type of reflection is not trivial (as our results and the literature bear out) but rarely occurs in beginning teachers (Ward \& McCotter, 2004). Thus, Transformative reflection is also removed in time from the reflection that can be captured by the other three levels (Routine, Technical and Dialogic) during pre-service teacher education.

\section{Educational significance}

Developing pre-service teachers' ability to reflect deeply and overcome their initial self-focused concerns is an important goal of teacher education. Our study indicates that Ward and McCotter's (2004) Reflection Rubric to evaluate preservice teachers' reflections on specific aspects of teaching practice (i.e., assessment, the role of content knowledge, pedagogical choices, differentiating instruction, and improving one's practice through formal inquiry) may also be a useful measure of SRL. We propose, however, that the levels could be adapted to more fully assess SRL by including descriptions of motivational and strategic components more directly. An adapted Transformative level may also be able to capture the most effective and adaptive (highest-SRL) reflections, and may be useful as a time-dependent measure after teaching practice has commenced.

One limitation, however, of the Ward and McCotter (2004) Reflection Rubric is that it does not make explicit the links between theory and practice within any of the levels. While the Transformative level does implicitly refer to theory through the teacher's consideration of "critical texts" (p., 250), this does not necessarily imply that theory should be guiding practice. Similarly, the role of theory in the development of adaptive expertise is underdeveloped (see 
Bransford et al., 2005). In self-regulated learning literature (which is not typically focused on teacher learning) the need for learners to refer to theory is also not necessarily made explicit, but rather is seen as task-dependent. In the SRL Rating Scale developed for this study using resources effectively is an indicator for Strategic Knowledge and Behaviour. In the context of teacher education and, more specifically, teacher reflections, such resources should explicitly involve links to theory and research.

The need for contextually sensitive authentic assessment has been discussed in relation to teacher education (Darling-Hammond \& Snyder, 2000) and to research on self-regulated learning (Perry, 2002). Instruments such as that developed by Ward \& McCotter (2004) and the SRL Rating Scale developed for this study may help advance our understanding of pre-service teachers' SRL as they engage in authentic tasks. The use of such instruments to better understand student teachers' learning processes may serve the ultimate goal of helping beginning teachers to make the transition from simplistic and self-focused reflections-on-action to the kinds of reflection-in-action that characterize adaptive expertise.

\section{References}

Bransford, J., Derry, S., Berliner, D. \& Hammerness, K., with Beckett, K.L. (2005). Theories of learning and their role in teaching. In L. Darling-Hammond \& J. Bransford (Eds.), Preparing teachers for a changing world: What teachers should learn and be able to do (pp. 40-87). San Francisco: Jossey-Bass.

Buzza, D., Kotsopoulos, D., \& Mueller, J. (2008, May). An investigation of teacher education candidates' responses to the Professional Development School model of teacher education. Paper presented at the Canadian Society for the Study of Education (CSSE), Canadian Association for Teacher Education (CATE), Vancouver, British Columbia.

Mueller, J., Buzza, D., \& Kotsopoulos, D. (2008, June). Technology integration and the construction of knowledge in a pre-service teacher education laptop program. Proceedings of the 2nd International Multi-Conference on Society, Cybernetics and Informatics, Orlando, FL, USA.

Collier, S. T. (1999). Characteristics of effective teachers. Journal of Teacher Education, 50 (3), 173-181.

Cruickshank, D. R., Kennedy, J. J., Williams, J., Holton, J. \& Fay, D. (1981). Evaluation of reflective teaching outcomes. Journal of Educational Research, 75(1), 26-32.

Darling-Hammond, L. \& Hammerness, K., with Grossman, P., Rust, F. \& Shulman, L. (2005). The design of teacher education programs. In L. Darling-Hammond \& J. Bransford (Eds.), Preparing teachers for a changing world: What teachers should learn and be able to do (pp. 390-441). San Francisco: Jossey-Bass.

Darling-Hammond, L. \& Snyder, J. (2000). Authentic assessment of teaching in context. Teaching and Teacher Education, 16(5), 523-545.

Dewey, J. (1933). How we think: A restatement of the relation of reflective thinking to the educative process. Boston: Heath.

Dinkelman, T. (2000). An inquiry into the development of critical reflection in secondary student teachers. Teaching and Teacher Education, 16, 195-222.

Flavell, J. H. (1979) Metacognition and cognitive monitoring: A new area of cognitivedevelopmental inquiry. American Psychologist, 34, 906-911.

Gore, J. \& Zeichner, K. (1991). Action research and reflective teaching in pre-service teacher education: A case study from the United States. Teaching and Teacher Education, 7, 119-136.

Hammerness, K., Darling-Hammond, L. \& Bransford, J., with Berliner, D., Cochrane-Smith, M., McDonald, M. \& Zeichner, K. (2005). How teachers learn and develop. In L. DarlingHammond \& J. Bransford (Eds.), Preparing teachers for a changing world: What teachers 
should learn and be able to do (pp. 358-389). San Francisco: Jossey-Bass.

Hatton, N. \& Smith, D. (1995). Reflection in teacher education: Towards definition and implementation. Teaching and Teacher Education, 11, 33-49.

Kremer-Hayon, L. \& Tillema, H. H. (1999). Self-regulated learning in the context of teacher education. Teaching and Teacher Education, 15, 507-522.

Merriam, S. B. (1988). Case study research in education: A qualitative approach (1st Ed.). San Francisco: Jossey-Bass.

Merriam, S. B. (1998). Qualitative research and case study applications in education. Thousand Oaks, CA: Sage.

National Research Council (2000). How people learn: Brain, mind, experience, and school (Expanded Ed.) Washington, DC: National Academies Press.

Paris, S. G. \& Newman, R. S. (1990). Developmental aspects of self-regulated learning. Educational Psychologist, 25, 87-102.

Perry, N. E. (2002). Introduction: Using qualitative methods to enrich understandings of selfregulated learning. Educational Psychologist, 37(1), 1-3.

Perry, N. E. \& VandeKamp, K. J. O. (2000). Creating classroom contexts that support young children's development of self-regulated learning. International Journal of Educational Research, 33, 821-843.

Schön, D. A. (1983). The reflective practitioner: How professionals think in action. New York: Basic Books.

Shulman, L. S. (1987). The wisdom of practice: Managing complexity in medicine and teaching. In D. C. Berliner and B. V. Rosenshine (Eds.), Talks to teachers: Afestschrift for N. L. Gage. New York: Random House.

Stake, R. (1995). The art of case study research. Thousand Oaks, CA: Sage Publications.

Stake, R. (2000). Case studies. In N. K. Denzin \& Y. S. Lincoln (Eds.), Handbook of qualitative research (pp. 435-454). Thousand Oaks, CA: Sage Publications.

Taylor, N. \& Corrigan, G. (2005). Empowerment and confidence: Preservice teachers learning to teach science through a program of self-regulated learning. Canadian Journal of Science, Mathematics, and Technology Education, 5(1), 41-60.

Tillema, H. H. \& Kremer-Hayon, L. (2002). "Practising what we preach" - teacher educators' dilemmas in promoting self-regulated learning: A cross-case comparison. Teaching and Teacher Education, 18, 593-607.

Ward, J. R. \& McCotter, S. S. (2004). Reflection as a visible outcome for pre-service teachers. Teaching and Teacher Education, 20, 243-257.

Ward, J. R. \& McCotter, S.S. (2004). Reflection as a visible outcome for pre-service teachers. Teaching and Teacher Education, 20, 243-257.

Winne, P. H. (1995). Inherent details of self-regulated learning. Educational Psychologist, 30 , 173-187.

Winne, P. H., \& Hadwin, A. F. (2008). The weave of motivation and self-regulated learning. In D. H. Schunk \& B. J. Zimmerman (Eds.), Motivation and self-regulated learning: Theory, research, and applications (pp. 297-314). Mahwah, NJ: Lawrence Erlbaum Associates.

Winne, P. H., \& Hadwin, A. F. (1998). Studying as self-regulated engagement in learning. In D. Hacker, J. Dunlosky, \& A. Groesser (Eds.), Metacognition in educational theory and practice (pp. 277-304). Hillsdale, NJ: Erlbaum.

Winne, P.H. \& Perry, N. E. (2000). Measuring self-regulated learning. In P. Pintrich, M. Boekaerts \& M. Zeidner (Eds.), Handbook of self-regulation. Orlando, FL: Academic Press.

Yin, R. K. (1994). Case study research: Design and methods (2nd Ed.). Thousand Oaks, CA: Sage Publications.

Yost, D. S., Sentner, S. M. \& Forlenza-Bailey, A. (2000). An examination of the construct of critical reflection: Implications for teacher education programming in the $21^{\text {st }}$ century. Journal of Teacher Education, 51(1), 39-49.

Zimmerman, B.J. (1990). Self-regulated learning and academic achievement: An overview. Educational Psychologist, 25, 3-18.

Zimmerman, B. J. \& Schunk, D. H. (2001). Self-regulated learning and academic achievement: Theoretical perspectives. Mahwah, N.J.: Lawrence Erlbaum Associates. 
Dr. Dawn Buzza is an Associate Professor of Education at Wilfrid Laurier University. Her research interests include child and adolescent development and self-regulated learning (SRL). She is currently working in secondary schools to examine the effectiveness of teacher-developed SRL support strategies across instructional contexts and over time. Another research goal is to examine academic and motivational outcomes of SRL interventions for grade 9 students who have been identified as at risk for disengagement and school failure.dbuzza@wlu.ca

Donna Kotsopoulos is an Associate Professor in the Faculty of Education and in the Department of Mathematics in the Faculty of Science at Wilfrid Laurier University. Her research focuses on mathematical cognition and education.

Julie Mueller is an assistant professor in the Faculty of Education currently conducting research under a SSHRC grant examining teaching and learning in a digital age; and teaching courses at the undergraduate and graduate level in Learning and Child Development, Health and Physical Education Methods, and Integrating Technology, Pedagogy, and Content.

Megan Johnston is a PhD Candidate in Developmental Psychology at the University of Toronto; her research primarily focuses on moral development in adolescence. 